\title{
Comparative proteomic analysis between early developmental stages of the Coffea arabica fruits
}

\author{
G.B. Bandil' ${ }^{1}$ R.M. Etto ${ }^{2}$, C.W. Galvão ${ }^{2}$, H.J.O. Ramos ${ }^{3}$, E.M. Souza ${ }^{4}$, \\ F.O. Pedrosa ${ }^{4}$, D.F.S. Chaves ${ }^{4}$, L.F. Huergo ${ }^{4}$ and R.A. Ayub ${ }^{1}$ \\ ${ }^{1}$ Laboratório de Biotecnologia Vegetal, \\ Departamento de Fitotecnia e Fitossanidade, \\ Universidade Estadual de Ponta Grossa, Ponta Grossa, PR, Brasil \\ ${ }^{2}$ Laboratório de Biologia Molecular Microbiana, \\ Departamento de Biologia Estrutural, Molecular e Genética, \\ Universidade Estadual de Ponta Grossa, Ponta Grossa, PR, Brasil \\ ${ }^{3}$ Laboratório de Biologia Molecular de Plantas - Bioagro, \\ Departamento de Bioquímica e Biologia Molecular, \\ Universidade Federal de Viçosa, Viçosa, MG, Brasil \\ ${ }^{4}$ Laboratório de Fixação Biológica de Nitrogênio, \\ Departamento de Bioquímica e Biologia Molecular, \\ Universidade Federal do Paraná, Curitiba, PR, Brasil \\ Corresponding author: R.A. Ayub \\ E-mail: rayub@uepg.br
}

Genet. Mol. Res. 12 (4): 5102-5110 (2013)

Received March 21, 2013

Accepted September 20, 2013

Published October 29, 2013

DOI http://dx.doi.org/10.4238/2013.October.29.4

ABSTRACT. Coffee is one of the most valuable agricultural
commodities. There is much agronomic research on coffee, but molecular
knowledge of its fruit development and ripening is limited. This study
reports a comparative proteomic investigation of immature coffee fruits
in two early developmental stages: stage 1, cell division and elongation of
the perisperm; and stage 2, early growth of the endosperm progressively
replacing the perisperm. Proteins were extracted using a modified SDS-
phenol method and two-dimensional electrophoresis gels stained with 
Coomassie blue revealed about 300 well-resolved polypeptide spots in the $\mathrm{pH}$ range of 3 to 10 . The differentially expressed polypeptides spots were excised, trypsin-digested, and analyzed by MALDI-TOF mass spectrometry. Peptide MS data were searched against the coffee EST database. Most of the identified protein spots are involved in the glycolytic pathway and energy reserve, and are more highly expressed at stage 2.

Key words: Coffee; Growth; Immature fruit; Proteome

\section{INTRODUCTION}

Coffee is an important agricultural commodity produced in more than 60 countries worldwide. Brazil alone accounts for more than one third of the global coffee production and exportation (Vieira et al., 2006). The two main species cultivated in the world are Coffea arabica, which represents approximately $70 \%$ of world production, and Coffea canephora, which represents the remaining 30\% (Geromel et al., 2006). Because of the economic importance of coffee, a great amount of agronomic work has been done (Rogers et al., 1999a) such as on flowering, yield, bean size, cup quality, caffeine content, disease, and drought resistance (Vieira et al., 2006). Most of these studies focused on ripe fruit components such as caffeine, chlorogenic acids, trigonelline, diterpene, sucrose, and phenolic compounds (Mazzafera and Robinson, 2000; De Castro and Marraccini, 2006; Geromel et al., 2006). Furthermore, studies about changes in concentration of mono- and oligosaccharides, sugar alcohols, myo-inositol, carboxylic acids, inorganic anions (Rogers et al., 1999b), and ethylene in coffee during grain development were also reported (Pereira et al., 2005). The protein composition of the fruit was also the object of some coffee studies, because they are precursors of nitrogen compounds involved in the fruit flavor (Rogers et al., 1999a; Estanislau, 2002). Despite the wide spectrum of agronomic studies, the molecular knowledge of fruit development and ripening is still limited. A study of the coffee seed development using proteomics and two-dimensional (2-D) gels was reported recently. It focused on zygotic embryos at two later developmental stages, 210 and 255 days after anthesis (DAA), since coffee seed development is accompanied by severe modifications in water-soluble proteins and several of these are associated with a specific developmental stage (Franco et al., 2009).

Fruit development and ripening studies are important, because the pathways involved in these processes are unique to plants and vary between species. Although different species share common pathways and developmental programs, the physiological, anatomical, and biochemical compositions and structural differences must contribute to the operation of unique pathways, genes, and proteins (Katz et al., 2007). The elucidation of the molecular basis of such early and common events represents an active frontier in fruit ripening research (Giovannoni, 2004). Lemaire-Chamley et al. (2005) analyzed genes expressed from the early developing fruit of a tomato, using microarrays, and found a higher proportion of genes with unknown functions, suggesting that future studies on early tomato fruit development should preferentially focus on this stage, which is concomitant with the transition from cell division to cell expansion. Through the scale of the coffee fruit phenological stages, proposed by Pezzopane et al. (2003), cell division and cell expansion stages can be visually observed. The cell division and elongation of the perisperm stage, at 0 to $60 \mathrm{DAA}$, is characterized by intense cell division but with no change in fruit size (Pezzopane et al., 2003; De Castro and Marraccini, 2006). This absence of growth is associated with high levels of abscisic acid and low levels of gibberellic 
acid (Thomaziello et al., 2000). The cell expansion stage, at 60 to 90 DAA, is characterized by a rapid increase in fruit diameter, with gradual disappearing of the transient perisperm and the early endosperm expanding (Cutter, 1987; De Castro and Marraccini, 2006; Joët et al., 2009).

In this study, the proteomic profiles of two developmental stages of immature coffee (55 and 90 DAA) were compared to identify differentially expressed proteins and relate them to the metabolic pathways involved. The results may contribute to future studies about fruit development and growth using molecular strategies.

\section{MATERIAL AND METHODS}

\section{Plant materials}

C. arabica fruits of the IAPAR 59 cultivar were collected at two early developmental stages: stage 1 at 55 DAA, and stage 2 at 90 DAA. Stage 1 encompasses 50 to 60 DAA, which corresponds to the cell division and elongation of the perisperm, and stage 2 encompasses 85 to $95 \mathrm{DAA}$, which corresponds to the early growth of the endosperm progressively replacing the perisperm. Immediately after collection, the fruits were frozen in liquid nitrogen and stored at $-80^{\circ} \mathrm{C}$ until analysis.

\section{Preparation of total protein extracts}

Total proteins were extracted from the fruits according to the modified sodium SDSphenol method described by Wang et al. (2003). Grains were finely ground in a liquid nitrogen pre-cooled mortar by using a pestle. Approximately $2 \mathrm{~g}$ of the resulting tissue powder $(20$ $\mathrm{mL}$ ) was placed into a centrifuge tube and suspended in $20 \mathrm{~mL}$ extraction buffer I [containing $1 \%$ polyvinyl-polypyrrolidone, $2 \%$ 2-mercaptoethanol, $1 \mathrm{mM}$ phenylmethylsulfonyl fluoride (PMSF) in acetone]. The mixture was vortexed thoroughly for $30 \mathrm{~s}$, kept on ice, and sonicated for $20 \mathrm{~s}$ at $30 \%$ output of the sonicator (Fisher Scientific Sonic Dismembrator model 500). Samples were centrifuged $\left(15 \mathrm{~min}, 5525 \mathrm{~g}, 4^{\circ} \mathrm{C}\right)$ and the supernatant was discarded. The resulting pellet was washed twice with $15 \mathrm{~mL}$ ice-cold acetone, and each washing step was centrifuged at $5525 \mathrm{~g}$ for $5 \mathrm{~min}$ at $4^{\circ} \mathrm{C}$. The pellet was resuspended three times in $15 \mathrm{~mL}$ of cold 10\% trichloroacetic acid (TCA) in acetone. After that, it was washed twice with cold aqueous $10 \%$ TCA and twice with cold $80 \%$ acetone. A final wash was performed with cold $80 \%$ ethanol. Each time, the pellet was resuspended completely by vortexing and was then centrifuged as described above. The final pellet was dried at room temperature for about $16 \mathrm{~h}$.

The pellet obtained was resuspended in $10 \mathrm{~mL}$ extraction buffer II (containing 30\% sucrose, 2\% SDS, $0.1 \mathrm{M}$ Tris-HCl, $\mathrm{pH} 8,2 \%$ 2-mercaptoethanol, and $1 \mathrm{mM}$ PMSF) and immediately vortexed thoroughly for $30 \mathrm{~s}$. It was then kept at room temperature for $20 \mathrm{~min}$. Then, 12 $\mathrm{mL}$ Tris-HCl saturated with phenol, $\mathrm{pH} 8$, was added, and the mixture was vortexed thoroughly three times for $40 \mathrm{~s}$ each. The sample was then incubated on ice for $5 \mathrm{~min}$. The phenol phase was separated by centrifugation at $5525 \mathrm{~g}$ for $5 \mathrm{~min}$ at $4^{\circ} \mathrm{C}$. The upper phenol phase was collected in centrifuge tubes (approximately $10 \mathrm{~mL}$ ). Proteins in the phenol phase were precipitated in 3 volumes of cold $0.1 \mathrm{M}$ ammonium acetate in methanol at $20^{\circ} \mathrm{C}$ for $40 \mathrm{~min}$. Precipitated proteins were recovered through centrifugation at $5525 \mathrm{~g}$ for $10 \mathrm{~min}$ at $4^{\circ} \mathrm{C}$, washed twice with $15 \mathrm{~mL}$ cold $0.1 \mathrm{M}$ ammonium acetate, and then centrifuged again at $2000 \mathrm{~g}$ for $5 \mathrm{~min}$ at $4^{\circ} \mathrm{C}$. The resulting pellet was washed twice with $15 \mathrm{~mL}$ cold $0.1 \mathrm{M}$ ammonium acetate, three times 
with cold $80 \%$ acetone, and once with cold $80 \%$ ethanol. After each washing, the pellet was resuspended completely by vortexing and then centrifuged at $5525 \mathrm{~g}$ for $5 \mathrm{~min}$ at $4^{\circ} \mathrm{C}$.

The resulting pellet was dried at room temperature for about $24 \mathrm{~h}$, and then was dissolved in $400 \mu \mathrm{L}$ buffer [7 M urea, $2 \mathrm{M}$ thiourea, $4 \%$ CHAPS, and $40 \mathrm{mM}$ dithiothreitol (DTT)] and stored at $-20^{\circ} \mathrm{C}$. The total protein content was estimated according to Bradford (1976).

\section{Two-dimensional electrophoresis}

Isoelectric focusing and molecular mass separation were conducted using an IPGphor II and an SE 600 Ruby according to the manufacturer protocol (GE Healthcare). Approximately $600 \mu \mathrm{g}$ protein was applied on 11-cm strips with a linear $\mathrm{pH}$ range from 3 to 10 (GE Healthcare). Isoelectric focusing was performed at $20^{\circ} \mathrm{C}$, with cur $\neg$ rent limited to $50 \mu \mathrm{A} /$ strip and applying $500(4 \mathrm{x}), 800,7000$, and $3700 \mathrm{Vh}$. The strips were equilibrated in buffer (6 M urea, $75 \mathrm{mM}$ Tris-HCl, $\mathrm{pH} 8.8,29.3 \%$ glycerol, $2 \%$ SDS, and $0.002 \%$ bromophenol) containing $1 \%$ DTT (w/v) for $15 \mathrm{~min}$, followed by a $15 \mathrm{~min}$ incubation in the same buffer without DTT and containing $2.5 \%$ iodoacetamide (w/v) according to GE Healthcare. The second dimension was carried out on an $18 \times 18 \mathrm{~cm} 11.7 \%$ gel via SDS-PAGE. The gels were stained with Coomassie blue R250.

\section{Gel image analysis}

Images were captured by scanning the gels with an Image Scanner (GE Healthcare) and LabScan software (GE Healthcare) and were analyzed by the ImageMaster2D Platinum 6.0 software (GE Healthcare). Three gels were analyzed per sample. The gels that presented more spots were chosen as the reference. The individual spot intensity volume was normalized using the total intensity volume (sum of the intensity volumes obtained from all spots in the same 2-D electrophoresis gel). The normalized intensity volume values of individual protein spots were then used to determine the differential protein expression between stages. 2-D spots that exhibited a 1.5-fold or more decrease or increase were excised for identification by MALDI-TOF mass spectrometry.

\section{Protein digestion and identification}

Spots were excised from the 2-D gels and subjected to overnight incubation with sequencing-grade trypsin, as described by Westermeier and Naven (2004). The samples were desalted using Perfect Pure C-18 tips (Eppendorf) according to the manufacturer protocol, and the peptides were eluted using $1 \mu \mathrm{L}$ of a freshly prepared $10 \mathrm{~g} / \mathrm{L}$ solution of 4-hydroxy$\alpha$-cyanocinnamic acid in $0.1 \%$ TFA (v/v) and $50 \%$ methanol $(\mathrm{v} / \mathrm{v})$. This sample was applied onto a MALDI-TOF target and allowed to dry. Mass spectra in the $\mathrm{m} / \mathrm{z}$ range of 800 to 3200 were acquired using a MALDI-TOF mass spectrometer (Bruker Daltonics) operating in positive reflection mode and pre-calibrated with a mixture of mass standards. Monoisotopic mass peaks lists were created using Flex Analysis 3.0 (Bruker Daltonics). When trypsin autolysis peaks were identified, they were used as internal mass calibrants. Protein identification by peptide mass fingerprinting was performed using the PiumsGUI software (Samuelsson et al., 2004) running locally, and multiple MS1 searches were made automatically. In the search parameters, carbamidomethylation was set as a fixed modification and methionine oxidation as a variable one, one missed cleavage was allowed, and the monoisotopic mass error was less 
than $100 \mathrm{ppm}$. The searches were performed against $C$. arabica and C. canephora EST-based protein databases that were obtained from the HarvEST search engine software (http://harvest. ucr.edu/). For positive match, we used the search criteria of at least five peptides showing matches with a minimal score of 5.0 and P-value below 0.05 . Additionally, positive protein assignments required greater than $15 \%$ sequence coverage and less than $25 \%$ deviation between theoretical and experimental MW and pI values obtained from calibrated 2-D gels. NCBIBLAST (http://www.ncbi.nlm.nih.gov) was used to find the known function of a protein for the corresponding sequences obtained from PIUMS.

\section{RESULTS AND DISCUSSION}

\section{Comparative analysis of proteomic maps}

In this study, 2-D gels of the two different fruit developmental stages (stage 1, at 55 DAA; and stage 2, at 90 DAA) were compared using immobilized gradient strips with a $\mathrm{pH}$ range of 3 to 10. All 2-D gels from each condition assessed were analyzed using the same parameters of hue, contrast, and sharpness. Similar profiles were found between stage 1 (Figure 1A) and stage 2 (Figure 1B), with approximately 300 well-resolved polypeptide spots distributed throughout the gel. Most of these spots ranged in mass from 22 to $66 \mathrm{kDa}$ and in pI from 4.0 to 7.0. Proteomic analysis of later coffee seed maturation stages (210 and 255 DAA) showed a profile with approximately 185 spots, mostly with $\mathrm{pI}$ varying from 5.0 to 7.0 and mass from 10 to $115 \mathrm{kDa}$ (Franco et al., 2009). The variation in the number of expressed proteins in the early and later fruit developmental stages reflects the characteristic metabolism of each phase. In the early developmental stages of $C$. arabica fruit, the perisperm is the site of biosynthesis of several important biochemical precursors that are then loaded, transformed, and stored in the mature endosperm. In the same way, the intense accumulation of storage compounds during endosperm development is preceded by import of amino acids and metabolites, such as sugars, in the perisperm (Geromel et al., 2006; Salmona et al., 2008; Joët et al., 2009). After the comparison between the reference gels of the two analyzed stages, statistical analysis pointed out six protein spots that were differentially expressed (Table 1 and Figure 1A and B).

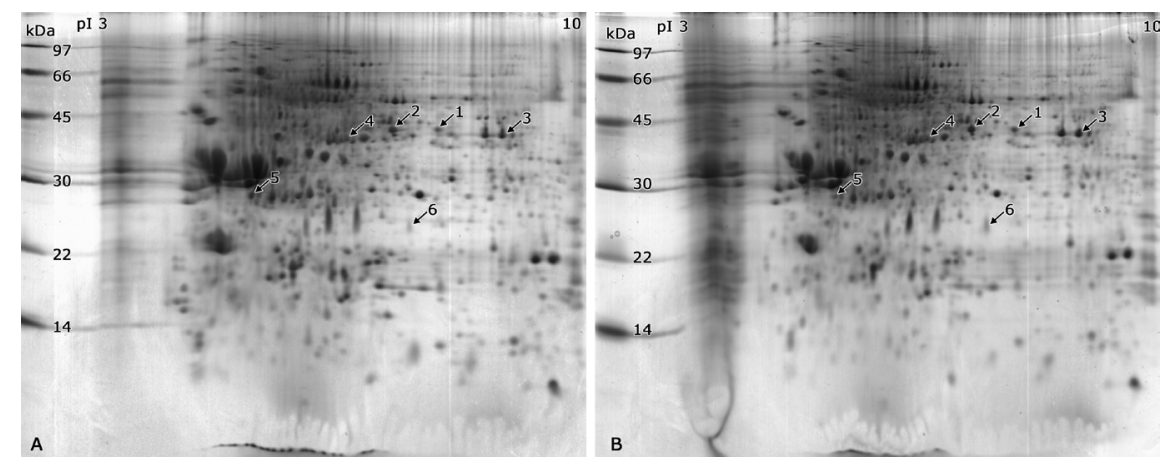

Figure 1. Two-dimensional electrophoresis images of coffee fruits proteins expressed in stage 1 (55 DAA) (A) and stage 2 of development (90 DAA) (B). Total extract proteins separated by a strip of $11 \mathrm{~cm}$ with a pH gradient 3-10, followed by a vertical electrophoresis SDS-PAGE $11.7 \%$ acrylamide $(18 \times 18 \mathrm{~cm})$ and subsequently stained with Coomassie blue. 
Table 1. Statistical analysis of differentially expressed protein spots between stages 1 and 2.

\begin{tabular}{|c|c|c|c|c|c|c|}
\hline Spot $^{\mathrm{a}}$ & Relative expression of the spot ${ }^{\mathrm{b}}$ & Mean $(100 \%)^{\mathrm{c}}$ & M.S.D. ${ }^{d}$ & $\%$ Vol stage $1^{\mathrm{e}}$ & $\%$ Vol stage $2^{\mathrm{f}}$ & $t$-test $\mathrm{t}^{\mathrm{g}}$ \\
\hline 1 & 1.53074 & 0.496149 & 0.1128 & 0.383736 & 0.608562 & 17.3273 \\
\hline 2 & 1.50008 & 0.238891 & 0.0801 & 0.164603 & 0.31318 & 3.50975 \\
\hline 3 & 1.71979 & 0.521646 & 0.1458 & 0.37608 & 0.667213 & 25.0036 \\
\hline 4 & 1.50811 & 0.26405 & 0.0571 & 0.207099 & 0.321002 & 23.7493 \\
\hline 5 & 1.56565 & 0.29728 & 0.0948 & 0.385811 & 0.208749 & 3.6955 \\
\hline 6 & 1.84539 & 0.122433 & 0.0531 & 0.0717643 & 0.173101 & 4.48462 \\
\hline
\end{tabular}

${ }^{\mathrm{a} S p o t}$ number. ${ }^{\mathrm{b}}$ Ratio value inter-class analysis, expressed as volume percentage, indicates that the spots are at least 1.5 times higher or lower in one of the stages than the other one. 'Sum of all the sample values divided by the sample size. ${ }^{\mathrm{d}}$ Mean squared deviation, the square root of the average squared difference of each sample value to the center location. ${ }^{\mathrm{e}} \mathrm{Center}$ value of spots from stage 1 expressed as volume percentage. ${ }^{\mathrm{f} C e n t e r}$ value of spots from stage 2 expressed as volume percentage. ${ }^{\mathrm{g}}$ Two-sample $t$-test indicates that the difference between the two stages is statistically significant when this value is larger than a certain threshold (Westermeier and Naven, 2004). The threshold chosen was 1.5 .

\section{Mass spectrometry protein identification}

The differentially expressed protein spots were subjected to trypsin digestion and MALDI-TOF analysis and were then identified (Table 2).

\begin{tabular}{|c|c|c|c|c|c|c|c|c|c|}
\hline Protein $^{\mathrm{a}}$ & Spot No. ${ }^{b}$ & $\begin{array}{c}\text { NCBI } \\
\text { cccession No. }^{c}\end{array}$ & Species $^{d}$ & Score $^{e}$ & $\mathrm{pI}^{\mathrm{f}}$ & $\mathrm{MW}^{\mathrm{g}}$ & P value ${ }^{\text {h }}$ & $\begin{array}{c}\text { Identical } \\
\text { masses }^{i}\end{array}$ & Coverage $\mathrm{j}^{\mathrm{j}}$ \\
\hline Fructose bisphosphate aldolase & 1 & P29356.1 & Spinacia oleracea & 39.99 & $7.8(8.3)$ & $44(38)$ & 0 & $11 / 27$ & 48.1 \\
\hline Fructose bisphosphate aldolase & 2 & P29356.1 & Spinacia oleracea & 52.46 & $7.2(6.9)$ & $43(38)$ & 0 & $16 / 51$ & 52.7 \\
\hline $\begin{array}{l}\text { Glyceraldehyde-3-phosphate } \\
\text { dehydrogenase }\end{array}$ & 3 & P25861.1 & Antirrhinum majus & 43.01 & $8.7(8.5)$ & $42(36)$ & 0 & $13 / 35$ & 56.4 \\
\hline Cytosolic malate dehydrogenase & 4 & Q08062.2 & Zea mays & 28.32 & $6.5(6.3)$ & $40(35)$ & 0 & $9 / 39$ & 35.6 \\
\hline Thaumatin & 5 & P13046.1 & Nicotiana tabacum & 21.05 & $5.2(5.2)$ & $29(24)$ & 0.005 & $5 / 32$ & 25.4 \\
\hline Protein 11S & 6 & P13744.1 & Cucurbita maxima & 23.07 & $7.4(6.5)$ & $26(54)$ & 0.011 & $7 / 21$ & 14.1 \\
\hline
\end{tabular}

Peptides mass fingerprint (PMF) allowed the identification of corresponding proteins by using PIUMS and Coffea ESTs data. a'Identified protein based on MS analysis of spots excised from fruit coffee 2-D gels. ${ }^{\text {bSpot numbers }}$ correlated with those from Figure 1. ${ }^{\mathrm{N} C B I}$ accession No. of the respective species. ${ }^{\mathrm{d}}$ Species that showed the

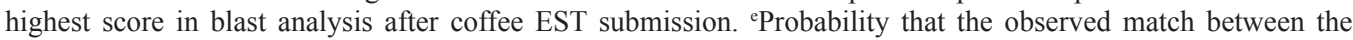
experimental data and the database sequence is a random event, expressed as $-10 * \log (\mathrm{P})$. ${ }^{\mathrm{f}}$ Observed isoelectric point (theoretical). ${ }^{\mathrm{g}}$ Observed molecular weight (theoretical). ${ }^{\mathrm{h} S t a t i s t i c a l}$ probability that the observed degree of matching would be found by chance. ${ }^{i}$ Number of matched/searched peaks. ${ }^{~}$ Percentage of sequence coverage calculated by dividing the number of amino acids observed by the protein amino acid length.

Protein spots $1 / 2,3$, and 4 , detected in higher amount in stage 2 (Table 1), were identified as fructose bisphosphate aldolase, glyceraldehyde-3-phosphate dehydrogenase, and cytosolic malate dehydrogenase, respectively (Table 2). The enzymes fructose bisphosphate aldolase and glyceraldehyde-3-phosphate dehydrogenase have also been identified in proteomic studies of apple, strawberry (Zheng et al., 2007), and tomato (Faurobert et al., 2007). Malate dehydrogenase has been identified in citrus studies (Katz et al., 2007). Despite the fact that both enzymes are involved in carbohydrate anabolism and catabolism, their higher expression in stage 2 suggests activation of the glycolytic pathway.

Stage 2 represents the perisperm-endosperm early transition. The early development of the coffee seed (transient perisperm) is characterized by active starch biosynthesis, with a 
high proportion of glucose derived from sucrose catabolism, the major carbohydrate transported in the phloem of coffee trees (Geromel et al., 2006; Joët et al., 2009). When the endosperm started expanding, the glucose content dropped and lipids and chlorogenic acids started to accumulate. In this stage, the glucose is metabolized by glycolysis and utilized as the carbon skeleton source, and provides energy for lipids and chlorogenic acids syntheses (Geromel et al., 2006; Lepelley et al., 2007; Joët et al., 2009; Troncoso-Ponce et al., 2009).

Two different spots ( 1 and 2 ) were identified as fructose bisphosphate aldolase, suggesting the presence of a posttranslational modification event that changed the observed $\mathrm{pI}$ from 7.2 to 7.8 without significant changes in the protein molecular weight. Considering that plant glycolysis exists in both the cytosol and the plastid, and the parallel reactions are catalyzed by distinct nuclear-encoded isozymes (Plaxton, 1996), it is possible that these enzymes occupy distinct cell compartments.

The protein spot 5 , present in higher concentration in stage 1 (Table 1), was identified as thaumatin (Table 2) and may also be related to sugar metabolism. Thaumatin belongs to the thaumatin-like protein (TLP) family, which includes the sweet-tasting protein extracted from Thaumatococcus daniellii, a plant native to West Africa. This protein is on average 100,000 times sweeter than sugar (de Vos et al., 1985). The expression of TLPs is related to some stressors, such as osmotic stress in tomato (Rodrigo et al., 1991), salinity in maize (Frendo et al., 1992), and pathogen attack in beans (Ye et al., 1999). Analyses have revealed that one of the many genes induced by drought in carrot is a member of the thaumatin family (Jung et al., 2005). Pasternak et al. (2007) showed that oxidative stress-inducing agents might promote cell division in plant, a process that occurs intensively in this perisperm elongation phase (Pezzopane et al., 2003; De Castro and Marraccini, 2006). Therefore, the identification of thaumatin indicates that the coffee seed in the early developmental stage is under some stress condition. However, additional studies are necessary to identify the stress origin in stage 1.

The protein spot 6 , detected in higher concentrations in stage 2 (Table 1), was identified as the protein 11S (Table 2). The molecular and biochemical characterizations of the $11 \mathrm{~S}$ storage protein were performed by Rogers et al. (1999a). This protein is the major source of peptides and amino acids in the fruit endosperm. The accumulation of these proteins occurs throughout fruit development, and peaks in the first half of the period of fruit ripening, which corresponds to the phase of maximum expansion of endosperm grains (approximately 14 weeks after flowering) (Rogers et al., 1999a). These proteins have a relatively low content of the sulfur amino acids cysteine (1\%) and methionine $(0.6 \%)$, suggesting a limited role of these amino acids as precursors of aromas and flavors in coffee (Grosch, 2001).

In summary, six differentially expressed protein spots were identified by mass spectrometry. The majority of them are involved directly or indirectly in the carbohydrate metabolism of the immature fruit of $C$. arabica, possibly due to the requirement of immediate energy for development. This proteomic study contributes to a better understanding of the early developmental stage of the coffee fruit, and shows that during the perisperm elongation and the early perisperm replacement by endosperm, there are only a few metabolic changes detectable by the 2-D electrophoresis technique.

\section{ACKNOWLEDGMENTS}

Research supported by Fundação Araucária, UEPG, UFPR, IAPAR, CNPq, National Institute of Science and Technology on Biological Nitrogen Fixation (INCT-FBN/CNPq-MCT) and CAPES. 


\section{REFERENCES}

Bradford MM (1976). A rapid and sensitive method for the quantitation of microgram quantities of protein utilizing the principle of protein-dye binding. Anal. Biochem. 72: 248-254.

Cutter EG (1987). Anatomia Vegetal. Traduzido por Gabriela Vera Maria Caruso Catena. Parte I. Células e Tecidos. Rocca, São Paulo.

De Castro RD and Marraccini P (2006). Cytology, biochemistry and molecular changes during coffee fruit development. Braz. J. Plant Physiol. 18: 175-199.

de Vos AM, Hatada M, van der Wel H, Krabbendam H, et al. (1985). Three-dimensional structure of thaumatin I, an intensely sweet protein. Proc. Natl. Acad. Sci. U. S. A. 82: 1406-1409.

Estanislau WT (2002). Modelo Funcional de Desenvolvimento de Sementes de Cafeeiro (Coffea arabica L.). Master's thesis, Lavras.

Faurobert M, Mihr C, Bertin N, Pawlowski T, et al. (2007). Major proteome variations associated with cherry tomato pericarp development and ripening. Plant Physiol. 143: 1327-1346.

Franco OL, Pelegrini PB, Gomes CP, Souza A, et al. (2009). Proteomic evaluation of coffee zygotic embryos in two different stages of seed development. Plant Physiol. Biochem. 47: 1046-1050.

Frendo P, Didierjean L, Passelegue E and Burkard G (1992). Abiotic stresses induce a thaumatin-like protein in maize; cDNA isolation and sequence analysis. Plant Sci. 85: 61-69.

Geromel C, Ferreira LP, Guerreiro SM, Cavalari AA, et al. (2006). Biochemical and genomic analysis of sucrose metabolism during coffee (Coffea arabica) fruit development. J. Exp. Bot. 57: 3243-3258.

Giovannoni JJ (2004). Genetic regulation of fruit development and ripening. Plant Cell 16 (Suppl): S170-S180.

Grosch W (2001). Volatile Compounds. In: Coffee: Recent Developments (Clarke RJ and Vitzthum OG, eds.). Blackwell Science, Oxford, 68-89.

Joët T, Laffargue A, Salmona J, Doulbeau S, et al. (2009). Metabolic pathways in tropical dicotyledonous albuminous seeds: Coffea arabica as a case study. New Phytol. 182: 146-162.

Jung YC, Lee HJ, Yum SS, Soh WY, et al. (2005). Drought-inducible-but ABA-independent-thaumatin-like protein from carrot (Daucus carota L.). Plant Cell Rep. 24: 366-373.

Katz E, Fon M, Lee YJ, Phinney BS, et al. (2007). The citrus fruit proteome: insights into citrus fruit metabolism. Planta 226: 989-1005.

Lemaire-Chamley M, Petit J, Garcia V, Just D, et al. (2005). Changes in transcriptional profiles are associated with early fruit tissue specialization in tomato. Plant Physiol. 139: 750-769.

Lepelley M, Cheminade G, Tremillon N, Simkin A, et al. (2007). Chlorogenic acid synthesis in coffee: An analysis of CGA content and real-time RT-PCR expression of HCT, HQT, C3H1, and CCoAOMT1 genes during grain development in C. canephora. Plant Sci. 172: 978-996.

Mazzafera P and Robinson SP (2000). Characterization of polyphenol oxidase in coffee. Phytochemistry 55: 285-296.

Pasternak TP, Ötvös K, Domoki M and Fehér A (2007). Linked activation of cell division and oxidative stress defense in alfalfa leaf protoplast-derived cells is dependent on exogenous auxin. Plant Growth Regul. 51: 109-117.

Pereira LFP, Galvão RM, Kobayashi AK, Cação SMB, et al. (2005). Ethylene production and acc oxidase gene expression during fruit ripening of Coffea arabica L. Braz. J. Plant Physiol. 17: 283-289.

Pezzopane JRM, Júnior MJP, Thomaziello RA and Camargo MBP (2003). Coffee phenological stages evaluation scale. Bragantia 62: 499-505.

Plaxton WC (1996). The organization and regulation of plant glycolysis. Annu. Rev. Plant Physiol. Plant Mol. Biol. 47: 185-214.

Rodrigo I, Vera P, Frank R and Conejero V (1991). Identification of the viroid-induced tomato pathogenesis-related (PR) protein P23 as the thaumatin-like tomato protein NP24 associated with osmotic stress. Plant Mol. Biol. 16: 931-934.

Rogers WJ, Bézard G, Deshayes A, Meyer I, et al. (1999a). Biochemical and molecular characterization and expression of the 11S-type storage protein from Coffea arabica endosperm. Plant Physiol. Biochem. 37: 261-272.

Rogers WJ, Michaux S, Bastin M and Bucheli P (1999b). Changes to the content of sugars, sugar alcohols, myo-inositol, carboxylic acids and inorganic anions in developing grains from different varieties of Robusta (Coffea canephora) and Arabica (C. arabica) coffees. Plant Sci. 149: 115-123.

Salmona J, Dussert S, Descroix F, de Kochko A, et al. (2008). Deciphering transcriptional networks that govern Coffea arabica seed development using combined cDNA array and real-time RT-PCR approaches. Plant Mol. Biol. 66: 105-124.

Samuelsson J, Dalevi D, Levander F and Rognvaldsson T (2004). Modular, scriptable and automated analysis tools for high-throughput peptide mass fingerprinting. Bioinformatics 20: 3628-3635. 
Thomaziello RA, Fazuoli LC, Pezzopane JRM and Fahl JI (2000). Café Arábica: Cultura e Técnicas de Produção. IAC, Campinas.

Troncoso-Ponce MA, Kruger NJ, Ratcliffe G, Garces R, et al. (2009). Characterization of glycolytic initial metabolites and enzyme activities in developing sunflower (Helianthus annuus L.) seeds. Phytochemistry 70: 1117-1122.

Vieira LGE, Andrade AC, Colombo CA, Moraes AHA, et al. (2006). Brazilian coffee genome project: an EST-based genomic resource. Braz. J. Plant Physiol. 18: 95-108.

Wang W, Scali M, Vignani R, Spadafora A, et al. (2003). Protein extraction for two-dimensional electrophoresis from olive leaf, a plant tissue containing high levels of interfering compounds. Electrophoresis 24: 2369-2375.

Westermeier R and Naven T (2004). Part II: Course Manual, Step 9: In-Gel Digestion. In: Proteomic in Practice - A Laboratory Manual of Proteome Analysis (Westermeier R and Naven T, eds.). Wiley-VCH, Weinheim.

Ye XY, Wang HX and Ng TB (1999). First chromatographic isolation of an antifungal thaumatin-like protein from French bean legumes and demonstration of its antifungal activity. Biochem. Biophys. Res. Commun. 263: 130-134.

Zheng Q, Song J, Doncaster K, Rowland E, et al. (2007). Qualitative and quantitative evaluation of protein extraction protocols for apple and strawberry fruit suitable for two-dimensional electrophoresis and mass spectrometry analysis. J. Agric. Food Chem. 55: 1663-1673. 